\title{
A concepção de mundo científico e a organização perceptiva
}

\section{The conception of the scientific world and the perceptive organization}

\author{
FERNANDO ALVES GRUMICKER
}

\begin{abstract}
Resumo: O presente escrito visa antes uma conceitualização da concepção de mundo científico na obra A Estrutura das Revoluções Científicas (1962) de Thomas S. Kuhn (19221996) e, ao mesmo tempo, pretende seguir a discussão que gira em torno da epistemologia e da filosofia da ciência. O mundo científico dita o modo de proceder de uma comunidade de cientistas, suas práticas, metodologias e linguagem, do mesmo modo como dita as generalizações simbólicas no campo da linguagem e dita, enfim, a percepção de mundo de uma comunidade científica no interior de um paradigma. O presente escrito visa não apenas definir a concepção de mundo científico, como também, apontar as suas características no campo da filosofia da ciência, recorrendo à bibliografia do autor e a seus críticos. Assim, o papel pretende ser duplo, de um lado apontando as caracterizações da concepção mundo científico e, por outro lado, demonstrando a necessidade do paradigma para uma concepção de mundo.
\end{abstract}

Palavras-chave: Ciência. Paradigma. Mundo. Linguagem. Percepção.

Abstract: The present article aims firstly a conceptualization of the idea of scientific world in the 1962 Thomas S. Kuhn's work The Structure of Scientific Revolutions, and, at the same time, it intends to follow the discussion that revolves around epistemology and philosophy of science. The scientific world dictates the mode of proceeding of a community of scientists, their practices, methodologies and language, the same way it dictates the symbolic generalizations in the field of language and it dictates, finally, the perception of the world of a community of scientists inside a paradigm. The present work aims not only to define the concept of scientific world but also to indicate its characteristics in the field of philosophy of science, resorting to the author's bibliography and to his critics. Thus, the role intends to be dual, on one side indicating the characterizations of the concept of scientific world and, on the other side, demonstrating the necessity of the paradigm for a concept of world.

Key-Words: Science. Paradigm. World. Language. Perception.

\section{Mudanças de mundo}

Ao nos questionarmos sobre uma comunidade de cientistas e o compartilhamento de noções comuns aos mesmos nesta dada comunidade, somos levados a afirmar que a comunidade compartilha de uma visão de mundo semelhante, por certas razões de estarem inseridos em paradigma comum, com uma teoria definida e amplamente aceita, isto é, que os membros de uma comunidade dividem uma concepção de mundo, ao mesmo tempo que partilham de noções teóricas, perceptivas e práticas. Assim, o trabalho de Thomas. S Kuhn (1922-

\footnotetext{
${ }^{1}$ Discente do Curso de Filosofia pela Universidade Estadual Do Oeste Do Paraná (UNIOESTE), e bolsista através do Programa de Educação Tutorial (PET) de Filosofia. Email:grumickerfernando@gmail.com
} 
1996) e a sua obra A Estrutura das Revoluções Científicas (1962)2 nos proporciona uma definição mais rica e precisa que o mero tateio sobre as questões filosóficas e, em certo sentido, até mesmo sociais. Questões acerca de como é possível o compartilhamento de noções no interior de uma comunidade científica e de que modo compartilham de uma visão de mundo, ou ainda, o que seria o mundo do cientista? São questões que fomentam a discussão a respeito do modo pelo qual uma comunidade científica se resolve. De fato, tais questões estão estreitamente ligadas à filosofia da ciência e constituem aqui as questões que giram entorno da própria concepção de mundo científico à luz de a Estrutura de Kuhn.

A abordagem de Kuhn na qual delimita uma comunidade científica a coloca diretamente ligada à metáfora de que, uma comunidade científica necessariamente compartilha de uma visão de mundo, por esta razão estão de certo modo inseridos em um mundo diferente, ou seja, em um mundo científico. O que chamamos de mundo científico ou mundo do cientista está ligado ao que Kuhn denomina de ciência normal. Refere-se a um paradigma científico que dita as maneiras de proceder no interior da comunidade constituída por uma tradição de pesquisa.

Assim, não é novidade que o estudante estará sendo inserido em um paradigma científico conforme os padrões da prática, da percepção e da própria linguagem empregada pela comunidade, de modo que estará "vendo o que o cientista vê e respondendo o que o cientista responde" (Kuhn, 1997, p. 146) após ter sido inserido no paradigma científico.

Apesar de que a própria percepção do cientista pode mudar conforme as mudanças de paradigmas, isto é, que a concepção de mundo pode e realmente sofrem alterações, mudam conforme ocorrem as revoluções (rupturas epistemológicas), as teorias e quando o próprio paradigma entra em crise. Ocorrendo assim as mudanças de interpretações de fenômenos, até mesmo sobre os já observados 3 . No entanto, é dado ao paradigma que o mundo científico se resolve, isto é, a prática da ciência no interior de um paradigma é determinada pela tradição de pesquisa, do mesmo modo a percepção do cientista e a sua conduta ${ }^{4}$, assim, o paradigma que constituí os aspectos da comunidade científica na ciência normal, será o determinante do que chamamos de mundo científico, que se trata, pois, da prática da ciência ditada por um paradigma; a linguagem e principalmente a estrutura perceptiva dos sujeitos de uma comunidade científica inserida em uma tradição de pesquisa.

\footnotetext{
${ }^{2}$ Por simples questão de economia passaremos a chamar a obra A Estrutura das Revoluções Científicas de apenas Estrutura, como uma referência à obra.

${ }^{3}$ É como a figura do pato e do coelho, nos diz Kuhn, o cientista depois de uma ruptura de uma tradição de pesquisa ao adotar um novo paradigma, seria como se estivesse em um ambiente diferente.
} 


\section{A formação do mundo científico}

Um dos problemas que encontramos ao abordar uma comunidade de cientistas diz respeito à concepção de mundo compartilhada por eles, poderíamos dizer que o estudante ao estar inserindo-se em um paradigma científico aprende a prática da pesquisa através de modelos e exemplares, podemos afirmar que ele (o estudante) aprendendo as manipulações, os aspectos perceptivos do paradigma são aprendidos respectivamente, assim, o estudante passa a ver o que a comunidade científica vê, inserindo-se no paradigma científico é que o estudante irá compartilhar de noções comuns da comunidade através de conjuntos de relações perceptivas, práticas e teóricas. Deste modo, o estudante que adentra no interior de um paradigma terá a sua visão de mundo totalmente transposta. Kuhn nega um papel gradual que o estudante teria nas suas relações de aprendizado, assim, o estudante não teria de modo algum uma mudança perceptiva gradual, sua categorização de conceitos linguísticos a objetos reais, nem a sua percepção seria moldada gradativamente, no entanto, a sua mudança perceptiva (nova gestalt) seria definitiva, assim como o aspecto prático que guiará a pesquisa científica no interior do paradigma na ciência normal, após esta mudança, tanto perceptiva e teórica é que o estudante estará habitando o mundo do cientista e delimitado definitivamente a sua concepção de mundo.

A análise de Gigi Anne Horbatiuck Sedor em sua obra "Explorando o Mundo Científico”, procura descrever alguns dos aspectos em qual a visão kuhniana de ciência é pautada, de acordo à Sedor, um mundo científico se apresenta em um triplo aspecto e constitui um paradigma científico determinado, nos afirma que o sucesso de um paradigma apenas é possível "depois de uma comunidade comprometer-se com uma concepção de mundo" (SEDOR, 2006, 46), tal afirmação é notoriamente verificada em Kuhn, uma vez que nas primeiras páginas de a Estrutura nos diz que entende um paradigma como algo comum a toda a atividade científica.

\section{A concepção perceptiva do paradigma}

Kuhn ao referir-se ao aspecto perceptivo do paradigma científico recorre à psicologia da gestalt, pretendendo assim demonstrar sugestivas as maneiras pelas quais uma mudança visual pode servir como guia, apesar de ser um exemplo metafórico afirmar que "poderemos ser tentados a dizer que, após uma revolução, os cientistas reagem a um mundo diferente" (Kuhn, 1997, p. 146), para o entendimento de como as mudanças perceptivas do estudante ao adentrar em um paradigma científico são alteradas. $\mathrm{O}$ modo pelo qual o estudante estará sujeito a uma nova rede perceptiva ao adentrar em um paradigma científico serão como se o estudante começasse a usar lentes inversoras, assim, o paradigma serve como um requisito para a própria percepção. Afirma Kuhn: 
As bem conhecidas demonstrações relativas a uma alteração na forma (Gestalt) visual demonstram ser muito sugestivas, para protótipos elementares destas transformações. Aquilo que antes da revolução aparece como um pato no mundo do cientista transforma-se posteriormente num coelho. (KUHN, 1997, p. 146).

Do mesmo modo como um físico treinado em um programa de pesquisa no interior de um paradigma detêm de uma percepção diversa daquela do estudante. O estudante ao adentrar em um paradigma através de práticas de pesquisa, aprenderá como o cientista vê e assim estará sujeito a uma nova gestalt, no entanto, Kuhn atribui um papel importante aos modelos e exemplares, no seu artigo Reconsiderações Acerca dos Paradigmas (1989), estes exemplares que norteariam o modo de proceder em um determinado empreendimento científico e seria um dos componentes chave da matriz disciplinar. Para o estudante que adentra em um novo paradigma, segundo Kuhn, é como se ele começasse a usar lentes inversoras, assim, deixa de ser metafórico que o mundo pode mudar conforme uma mudança de paradigma, seja ele o mundo do quotidiano ou a interpretação de um fenômeno através de um paradigma teórico incomensurável.

\section{A concepção teórica do paradigma}

Claramente a percepção do estudante estará sujeita à exposição de modelos que fomentam uma nova perspectiva que, nas palavras de Kuhn (1977, p. 358) "fornecem ao grupo as analogias preferidas ou, quando profundamente defendidos, uma ontologia", no entanto, esta mudança da percepção não é apenas uma mudança visual, mas também intelectual. Assim, os componentes teóricos que compõe um paradigma que servem de modelos para a própria pesquisa científica baseiam-se antes na expressão da linguagem de uma comunidade científica, e as generalizações simbólicas servem como analogias para a experiência científica, este aspecto epistemológico da filosofia de Kuhn inversamente corrobora para a ideia de que a formação do mundo científico depende tanto dos aspectos perceptivos quanto linguísticos que uma comunidade partilha no interior de um paradigma. As generalizações simbólicas do campo da linguagem direcionam-se diretamente na aplicabilidade para com os exemplares. Assim, o nosso estudante hipotético ao estar aprendendo uma generalização simbólica, como fórmula ou lei cientifica, estará inversamente dirigindo-se a uma tradição de pesquisa segundo os seus modelos e exemplares para a resolução dos quebra-cabeças da ciência paradigmática.

É importante destacar que as generalizações simbólicas no campo da linguagem que poderiam de certo modo estarem ligados à definição de paradigma, ainda não são definitivas sem, no entanto, estarem ligadas ao mundo objetivo à qual 
tal linguagem ${ }^{5}$ faz referência, portanto, à taxonomia segundo a linguagem e denotações de objetos que são de extrema importância para as tradições de pesquisas em geral.

Kuhn usa o exemplo do menino Johnny que, em um passeio no zoológico consegue diferenciar com a ajuda do pai os patos, cisnes e gansos através da classificação por redes de semelhanças e diferenças (semelhantes a uma programação neurológica). Do mesmo modo, o cientista ao estar inserido em um paradigma aprenderá a classificação através de modelos e exemplares, formando assim o seu léxico e compartilhando com a comunidade as referências dos conceitos ao mundo objetivo, aqui as generalizações simbólicas podem cumprir o seu papel para referir-se à objetos da experiência e fenômenos segundo a linguagem empregada pela comunidade (assim como uma criança pode diferenciar por conjuntos após uma aprendizagem ostensiva, a diferença de patos e gansos, por uma simples comparação de seus pescoços). No entanto, independentemente da experiência o paradigma configura a rede conceitual do próprio conhecimento empírico, uma vez que a experiência na ausência de um paradigma vem a ser desorganizada. Assim, quando nos referimos que o estudante não habita o mundo científico de maneira gradual é dado ao fato de que o paradigma permite o conhecimento organizado desta experiência sensível.

Segundo a teoria do léxico de Kuhn, não é possível ainda uma linguagem neutra que separe o componente da experiência do componente nominal, uma vez que a taxonomia existente da comunidade de cientistas segue o paradigma e formam, pois, léxicos definidos e inter-relacionados com os objetos da experiência. Uma das posições de Kuhn que acaba rejeitando uma linguagem neutra ou artificial propostas pelos empiristas lógicos que pretenderia expressar as leis e proposições humanas sobre a natureza de uma maneira que se poderia atribuir valores de verdade e falsidade às proposições, mantendo assim uma posição naturalista acerca da linguagem. De acordo a Sedor (2006, p. 62) "um holismo parcial é da natureza da linguagem. $\mathrm{O}$ conhecimento do mundo e o das palavras são acessados, ao mesmo tempo, por meio da linguagem", este holismo diz respeito a abordagem segundo a qual, tanto o estudante quanto o cientista estão sujeitos à mudanças de linguagem e de mundos conforme ocorrem as mudanças de paradigmas e, no caso do estudante, conforme se insere em uma tradição de pesquisa.

\section{A prática}

A concepção prática do paradigma científico dita o que Kuhn denominou de exemplares segundo o modelo do trabalho científico, os exemplares históricos da

\footnotetext{
5 Em seu artigo Reconsiderações Acerca dos Paradigmas (1989) Kuhn faz uma analogia na qual comunidades científicas diferentes seriam como comunidades com linguagens diferentes, portanto, incomensuráveis entre si.
} 
prática da pesquisa ditam o modo de proceder de uma comunidade científica, assim, o modo pelo qual uma comunidade deve resolver quebra cabeças ou enigmas que surgem como anomalias. Tais exemplares podem ser transcritos para os manuais de aprendizado do estudante, podem aparecer como exercícios a serem resolvidos como problemas. Os exemplares que norteiam a prática da ciência normal é, pois, tanto intelectual quanto empírica. São estes exemplares compartilhados pela comunidade científica que envolvem regras para a própria prática da ciência e o modo de proceder de uma determinada comunidade. É claro que pela exposição aos exemplares o estudante estaria aprendendo o modo de proceder sobre determinadas situações-problemas, ainda, os exemplares seriam os definidores que norteariam a prática da ciência segundo regras definidas que delimitam a natureza da ciência.

Ao que se refere a estas regras que provêm dos paradigmas, levando em conta que a própria experiência perceptual, é entendida por Kuhn como um produto derivado do paradigma, torna-se inteligível que os exemplares segundo as regras para resoluções dos quebra-cabeças inevitavelmente podem deixar de ser explicadas segundo uma descrição detalhada e justificada. Isto é, por que o cientista procede deste modo e não de outro? Qual a justificativa da regra que norteia a prática da ciência? E quando o cientista não consegue explicar a sua própria prática? Podemos dizer que em casos onde a prática da ciência está em conformidade com a resolução de modelos e exemplares, como guias ou manual para o aparente progresso da ciência em um paradigma, o cientista nem sempre consegue explicar tal prática, é como se, após estar sujeito aos exemplares e modelos, estar fazendo certos procedimentos de maneira não-explicativa, isto não quer dizer que não se conheça o que se está fazendo. Polanyi afirma que em sujeitos em geral, principalmente ao se refere às questões práticas, a própria prática não é explicitavel, no sentido de que permanece não-implícito, ou indizível. Nesses casos, é de sugerir que o componente prático da ciência permanece tácito, isto é, trata-se de um conhecimento não explícito para a prática, um conhecimento que muito embora foge dos limites possíveis da linguagem. Nos diz Polanyi que:

For just as, owing to the ultimately tacit character of all our knowledge, we remain ever unable to say all that we know, so also, in view of the tacit character of meaning, we can never quite know what is implied in what we say (Polanyi, 2005, p. 99) ${ }^{6}$.

É interessante salientar que, apesar da prática da ciência estar em conformidade com a pesquisa cientifica na ausência de regras que delimitem a própria prática da pesquisa de maneira explícita, não torna a prática da ciência sem nenhum critério, mas ao contrário, trata-se de uma abordagem objetiva para com os

\footnotetext{
${ }^{6}$ Pois, assim, devido ao carácter ultimamente tácito do nosso conhecimento, continuamos sempre incapazes de dizer o que sabemos, também em vista do tácito carácter de significado, nunca podemos saber o que está implícito no que nós dizemos (tradução nossa).
} 
eventos, os dados da experiência e as observações, pois o que norteia a prática da ciência é antes o paradigma, como já foi dito anteriormente, não as regras para o procedimento científico, com efeito, apesar de que um paradigma apresente uma prática para a ciência ainda, ainda na ausência dela o procedimento de resoluções de quebra-cabeças, não deixa de existir.

Permanece tático, portanto, o modo de proceder do cientista no paradigma e, do estudante que adentra um paradigma e se dirige para o mundo objetivo, isto é, o mundo dos dados do qual recebe estímulos.

Assim, apenas após o treino do estudante é que ele poderá participar de um paradigma em comum de uma comunidade de cientistas, partilhará com eles uma concepção comum, estará desta maneira inserido em um mundo científico. $\mathrm{O}$ mundo científico que denominamos apenas metaforicamente até então, como uma dimensão que ditaria os aspectos práticos, perceptivos e teóricos de uma comunidade inserida em um paradigma, fazendo com que fosse como se, ao adentrar em um paradigma, tanto o estudante quanto o cientista estariam em um mundo diferente, aparece como se a metáfora fosse diluída, pois o que pertence a uma comunidade científica em particular é o paradigma que os sujeitos particulares compartilham, tal comunidade particular é, segundo Kuhn, uma definição isolada, particular, que seria o subconjunto de uma definição geral de paradigma. Portanto, o mundo do cientista é o mundo onde o cientista habita, não o mundo do poeta ou o mundo do quotidiano, assim, os aspectos deste mundo são dirigidos pelo próprio paradigma compartilhado pela comunidade.

A concepção de mundo científico se encontra diretamente ligada à ciência normal exposta por Kuhn em sua obra. Constitui o mundo científico um triplo aspecto em sua dimensão perceptiva (enquanto gestalt e observação), teórica (conceitos linguísticos e ontológicos) e prática (técnicos e instrumentais), tais aspectos são moldados pela formação do cientista no interior de um paradigma, estes aspecto caracterizadores do mundo científico, diz respeito à ciência normal colocada por Kuhn, onde, na ciência paradigmática a atividade científica consiste nas resoluções de "quebra-cabeças" ou enigmas. Tais enigmas quando não solucionados podem levar o paradigma científico em crise, o que Kuhn denomina de “anomalia” no interior de um paradigma.

O aspecto perceptivo molda a percepção de mundo de um grupo científico em uma área determinada, onde a gestalt é usada por Kuhn de maneira metafórica recorrendo à psicologia. $\mathrm{O}$ aspecto teórico remete à incomensurabilidade dos paradigmas de se comunicarem entre si, enquanto paradigmas denotam uma visão de mundo, ao mesmo tempo que a linguagem de um grupo de cientistas é moldada por conceitos próprios da comunidade. 
Ao que se refere à prática da ciência, consiste em um conceito fundamental da epistemologia kuhniana, onde um grupo de cientistas que se encontram inseridos em um paradigma, determinam seus trabalhos na resolução de enigmas como modelos de prática da pesquisa, moldados por exemplares, ainda na ausência de regras que delimitem e explicitem a prática, permanece ainda tácito ao cientista o caminho do seu próprio procedimento, de maneira que o cientista não consiga explicar. Tanto o aspecto perceptivo, teórico e prático fundamenta o mundo científico, que é a maneira pela qual a visão de mundo de uma comunidade científica é compartilhada.

\section{O mundo não muda com uma mudança de paradigma}

Ao que diz respeito à caracterização da atividade científica e a sua delimitação constituinte em A Estrutura, enquanto as definições de Kuhn, de maneira estrutural, trata-se de um engenho científico caracterizado por rupturas epistemológicas para o seu desenvolvimento, isto é, para o progresso da ciência ${ }^{7}$ exigem-se mudanças de paradigmas.

As opiniões de Kuhn referem-se mais à maneira pela qual se adquire um determinado conhecimento do que pela lógica dos produtos da pesquisa científica, neste aspecto, suas concepções que abarcam as questões acerca do desenvolvimento da ciência não estão muito distantes da concepção de Popper (1902-1994), uma vez que permanece a noção de que "após uma revolução científica, muitas manipulações e medições antigas tornam-se irrelevantes e são substituídas por outras" (Kuhn, 1979, p. 6). A ciência normal, descrita por Kuhn cumpre seu papel definitivo na concepção de mundo científico e seus aspectos. O que foi caracterizado por Kuhn diz respeito às "fases" estruturantes de uma determinada comunidade de cientistas em relação com a sua prática. Trata-se, portanto, do que foi chamado por Kuhn de ciência pré-paradigmática; paradigmática e ciência revolucionária, como estruturas determinantes do empreendimento científico.

A "ciência normal" se faz traduzível por ciência paradigmática, isto é dizer que, ao mesmo tempo que nos referimos à ciência normal como caracterizadora da prática visível de uma determinada ciência, a comunidade de cientistas toma como objeto de pesquisa o mundo. Também, admitindo a concepção de um paradigma vigente como um requisito enquanto organizador da percepção, linguagem e prática, admitimos inversamente uma pluralidade de mundos (ou visões de mundo enquanto gestalt), permitindo uma variedade de interpretações sobre observações e reações de estímulos a dados semelhantes. Kuhn em a Estrutura emprega o termo mundo (ou mundo do cientista) como um sinônimo de natureza, sendo essa o objeto

\footnotetext{
7 Permanece a posição de que a ciência para Kuhn (1997, p. 116) "está longe de ser um processo cumulativo obtido através de uma articulação do velho paradigma”, isto demonstra que a atividade científica não progride por cumulação de conhecimento, mas por rupturas epistemológicas.
} 
da investigação de uma dada comunidade de cientistas, maneira pela qual, tem tanto o mundo quanto a natureza como o seu objeto sendo ambos sinônimos. Paul Hoiningen-Huene, ao se referir à essa aparente tensão, nos diz que Kuhn divide o mundo em uma noção perceptiva e uma conceitual, mas que também coloca uma pluralidade de mundos, a saber, assim como a diferença kantiana entre aparência e coisa-em-si, Kuhn dá a entender em seu argumento uma pluralidade de mundos fenomênicos. Sobre isto, afirma Hoiningen-Huene:

Kuhn diagnoses the theory's plurality-of-phenomenal-worlds (or, alternatively, his views on the nonuniquenees of the relationship between the one worlds-in-itself and the many phenomenal words) as an essential break with an epistemological (HOININGENHUENE, 1993, p. 37) ${ }^{8}$.

Entre a teoria kantiana a respeito da aparência e coisa-em-si, sobre o que se pode conhecer e o ininteligível, Kuhn pressupõe que os paradigmas, por ditarem uma gestalt, também colocam diante dessa o compartilhamento de noções comuns aos homens da ciência. Justamente, dado à existência de paradigmas incomensuráveis entre si, também isto dá a entender a existência de diversas comunidades de pesquisas inseridas em paradigmas diferentes, com efeito, pressupõe-se várias visões de mundos pautadas por paradigmas concorrentes, por sua vez, acarreta uma ruptura no pensamento com a tradição epistemológica segundo a qual apenas pode existir um mundo-em-si em, dito isto, uma visão de mundo apenas pode fazer referência a um único mundo. Dito isto, a pluralidade de mundos da qual a epistemologia científica kuhniana faz referência, não é a de que existam apenas um paradigma mais próximo da verdade (qual pensaria um popperiano), mas por tratar-se de paradigmas incomensuráveis o desenvolvimento científico apenas pode se dar por rupturas.

O mundo do cientista é determinado pelo paradigma científico, não podemos, tomar o sentido do paradigma (apesar do seu pluralismo terminológico) de maneira dispersa ou afastada da concepção de ciência normal, uma vez que por esta resolver problemas e enigmas em seu interior, promover descobertas e um aparente progresso científico, também é incomensurável com outros que possuem, em geral, uma teoria que a comunidade é amplamente adepta.

Portanto, na ciência normal jamais ocorrerão mudanças de gestalt, pois é apenas possível com uma revolução ou ruptura com uma tradição de pesquisa no caso de estarmos diante de uma comunidade já adepta a um paradigma vigente. Daí que as mudanças perceptivas não modificam o mundo, rigorosamente falando, mas

\footnotetext{
${ }^{8}$ Kuhn diagnostica a tese da sua teoria da pluralidade de mundos fenomênicos (ou, alternativamente, suas opiniões sobre a não singularidade das relações entre os mundos-em-si e os muitos mundos fenomênicos) com uma essencial ruptura epistemológica (HOININGEN-HUENE, 1993, p. 36-37).
} 
trazem consigo toda uma estrutura perceptiva incomensurável com a anterior, fazendo com que o pesquisador e o estudante vejam um mundo diferente após uma revolução científica.

\section{A necessidade do mundo científico para a organização perceptual}

No artigo de Margaret Masterman "A natureza do paradigma”, ressalta muitas definições diferentes encontradas para o conceito de "paradigma", entre elas se encontram as noções de que é um manual para a orientação do cientista, uma nuance epistemológica, ou como uma fonte de instrumentos. Mas o que mais nos interessa, é a concepção de paradigma que fomenta uma visão de mundo, "como princípio organizador capaz de governar a própria percepção” (MASTERMAN, 1979, p. 79) de maneira com que o sujeito tenha uma concepção de como são as coisas e de como se comportam, com uma ontologia permissiva para certos estados coisas possíveis, contudo, permanece uma ligação entre o paradigma e a comunidade de cientistas, onde o próprio paradigma com suas definições teóricas e a linguagem, fomentam uma visão de mundo.

Em a Estrutura, as transformações perceptivas que ocorrem com as mudanças de paradigmas, ao mesmo tempo em que o próprio paradigma define a percepção do cientista, não se trata de algo meramente metafórico que o cientista ao presenciar uma ruptura epistemológica no interior do paradigma irá "ver algo diferente" (mas se trata de uma metáfora afirmar que é como se o mundo mudasse, uma vez que a percepção dos sujeitos sobre o mundo não faz com que se trate de um mundo diferente para todos).

Dizer que é necessária defender um mundo científico, para a organização perceptual é o mesmo que afirmar, no fundo, se faz necessário um paradigma que norteie a nossa percepção em geral, e no caso de comunidades científicas com tradições de pesquisas definidas, não é diferente.

Assim como uma teoria rejeitada também dizia como o mundo se comportava, o cientista não poderá organizar a sua própria percepção sem estar sujeito a uma teoria que o guie, isto é, como se os telescópios de Galileu não pudessem ser confiáveis sem uma teoria óptica que o descrevesse. Do mesmo modo, tampouco o estudante estará sujeito a uma mudança perceptiva de uma maneira genérica. A percepção guiada pelo paradigma que organiza a experiência dos membros de uma comunidade científica é, ao mesmo tempo, um auxílio pelo qual o cientista conseguirá perceber determinados fenômenos que muito embora não conseguiria na ausência de um paradigma que estruturasse a sua percepção, linguagem ou o modo de proceder para com a natureza (ou mundo objetivo).

O paradigma apresenta para o cientista o seu horizonte de possibilidades e junto consigo as suas limitações. Se uma anomalia que surge em uma tradição de 
pesquisa só pode ser percebida caso houver permissibilidade da ocorrência do fenômeno no mundo segundo o paradigma, caso o mesmo não dê conta de dar resoluções sem uma cláusula ad hoc ou hipóteses auxiliares, para manter a visão vigente, então o paradigma entra em crise e pode levar a uma ruptura de uma tradição de pesquisa, uma vez que é apenas possível que algo ocorra no mundo de acordo com uma teoria que a descreva e impeça (limite) certas outras ocorrências. Assim, o paradigma é a ferramenta para ver a natureza e o paradigma constitui o mundo científico. Deste modo, se entende a natureza é o agregado das experiências possíveis e dos fenômenos?.

Como um paradigma prescreve a prática da ciência, de um grupo específico de cientistas, dá também os exemplos preferidos em suas analogias, os exemplares da prática de resolução de problemas, maneira pela qual se os membros da comunidade são expostos aos problemas. É claro que cientistas recorrem à experiencia para elaborarem leis e hipóteses, como também testes dessas mesmas hipóteses, no entanto, o que queremos dizer quando afirmamos que por si só, a experiência não possibilita uma organização de percepção, já que antes de uma observação o paradigma dita uma visão de mundo, mas também, coloca horizonte de possibilidades de como o mundo deve funcionar e limita também o seu funcionamento.

Entre paradigmas concorrentes pode haver uma disparidade de reações a observações, segundo o autor "um estímulo de dado pode suscitar uma variedade de sensações" (Kuhn, 1989, p. 370), assim, os membros de uma comunidade científica que receberam uma instrução, partilham da mesma literatura de formação, tendem a responder a estímulos dados com sensações parecidas, ao contrário porém, em um paradigma restrito onde os seus membros aprenderam a responder a dados com estímulos diferentes, as respostas não são inatas, mas os membros de uma comunidade é instruído a ver o mundo de acordo com uma estrutura de percepção. Também aqui, membros de paradigmas diferentes apresentam reações a dados semelhantes, mas com estímulos (reações) diferentes, nota-se que a relação com visões de mundo incomensuráveis entre si, tão necessária à comunidade quando se trata de se comunicar observações e reações, afirma Kuhn que em comunidades diferentes, apesar de cientistas serem colocados em situações semelhantes de dados, irão reagir com estímulos diferentes, igualmente à concepção pela qual comunidades de paradigmas diferentes são como falantes de idiomas diferentes uma vez que não se trata de uma mera organização de percepção, mas que vai além disso, no sentido de dar através de exemplares e modelos, maneiras de orientação de

\footnotetext{
9 Poder-se-ia objetar que o mundo científico aqui é a posição assumida por Kant a respeito do mundo material e dos fenômenos, no entanto, o mundo científico na definição kuhniana apenas condiz com Kant no sentido de admitir um mundo dos fenômenos, isto é, um mundo objetivo, no qual o paradigma estaria direcionado como um dirigente e organizador da prática, da linguagem e da própria concepção teórica nas ciências.
} 
pesquisas e de resolução de problemas, uma que na ausência de paradigmas que norteiem a prática da ciência, também inexistem uma estrutura de percepção organizada segundo um modelo.

\section{Referências}

HOININGEN-HUENE, P. Reconstructing scientific revolutions. Chicago: The Univ. Chicago Press, 1993.

KUHN, T. A estrutura das revoluções científicas. 5. ed. São Paulo: Perspectiva, 1997.

. Reconsiderações acerca dos paradigmas. In: KUHN, T.S, 1989.

MASTERMAN, M. “A natureza do paradigma”. In: Lakatos, I. \& Musgrave, A. A crítica e o desenvolvimento do conhecimento. São Paulo: Cultrix, 1997, p. 72-108.

POLANYI, M. Conhecimento pessoal. London: Taylor \& Francis, 2005.

SEDOR, G. A. H. Thomas S. Kuhn: explorando o mundo científico. Florianópolis: Edição de Autor, 2006.

Submissão: 28. 11. $2020 \quad$ / Aceite: 10. 02. 2021 